\title{
Convergent Validity Analysis between the Profile of Emotional Competences Full-Form and the Trait Emotional Intelligence Questionnaire Full-Form
}

\author{
Sylvain Laborde ${ }^{1,2}$ (D) Félix Guillén ${ }^{3} \cdot$ Robert Vaughan $^{4}$
}

Accepted: 2 April 2021/ Published online: 26 April 2021

(C) The Author(s) 2021

\begin{abstract}
Emotional dispositions have been found to influence outcomes and have applications in many areas, such as in the clinical, health, social, educational, and organizational domains. Specifically, they may influence individuals' addictive behaviour tendencies. The aim of this study was to investigate the convergent validity between two questionnaires measuring individual differences linked to emotional dispositions, the Profile of Emotional Competences (PEC) full-form, and the Trait Emotional Intelligence Questionnaire (TEIQue) full-form. Examining the convergent validity will identify the similarities and the unique aspects of each questionnaire. Our hypotheses were based on relationships displaying large effect sizes $(r>.50)$. A sample of 1026 participants took part in this study $\left(M_{\text {age }}=21.35\right.$ years old, age range $\left.=18-30\right)$. Participants completed both the PEC and the TEIQue in a counterbalanced order. Results indicated large overlaps between the two questionnaires; however, two main differences emerged: first, the PEC allows capturing precisely the emotional dispositions at the intrapersonal and interpersonal levels, while the TEIQue mixes both levels; second, the competence "using emotions", both for one's own emotions and for others' emotions, is not comprehensively reflected in the TEIQue. Overall, the PEC may help to capture more specifically the distinction between intrapersonal and interpersonal emotional competences. Future research should investigate comparatively the criterion validity of both questionnaires with specific outcome variables. Future research and applied work with addiction aiming at clarifying the implication of both intrapersonal and interpersonal emotional competences may consider to rather use the PEC than the TEIQue.
\end{abstract}

Keywords Emotional intelligence $\cdot$ Emotional competences $\cdot$ Emotion identification $\cdot$ Emotion expression $\cdot$ Emotion understanding $\cdot$ Emotion regulation $\cdot$ Emotion use

Sylvain Laborde

sylvain.laborde.unicaen@gmail.com

Extended author information available on the last page of the article 
Individual differences linked to emotional dispositions at the trait level have been referred to as trait emotional intelligence (EI) or emotional competences (EC). EI/EC refer to the selfperception of emotional abilities at a trait level, that is to say, the typical performance of people in terms of identifying, expressing, understanding, regulating, and using emotions, for themselves and for others, in order to adapt to their environment (Brasseur et al., 2013; Petrides et al., 2016; Scherer, 2007). The field of EI and EC at the trait level has applications in the areas of clinical, health, social, educational, organizational, and developmental psychology (Petrides et al., 2016; Sarrionandia \& Mikolajczak, 2020). Specifically regarding addiction, higher EI was found to be a protective factor against smoking (Kun \& Demetrovics, 2010; Torres et al., 2020), alcohol use, and illicit drug use (Kun \& Demetrovics, 2010). Furthermore, technological addictions are of recent interest (Gugliandolo et al., 2019), and EI has been found to be a protective factor against problematic internet behaviour (Arrivillaga et al., 2020; Hsieh et al., 2018; Sechi et al., 2020; Wang \& Zhang, 2020), and smartphone use (Arrivillaga et al., 2020; Busch \& McCarthy, 2021; Mascia et al., 2020). Finally, EI and EC may not only act as protective factors against addiction behaviours, but may also represent an important adjuvant for counsellors providing support for people with addiction, given addiction counsellors with higher EI have been found to display higher cultural empathy (Smith et al., 2020). Taken together, these findings showcase the societal relevance of EI and EC to better understand addiction.

Concerning terminology, EI has been mostly used since the concept was defined by Salovey and Mayer (1990). However, researchers have called for a terminology shift towards EC (Brasseur et al., 2013; Scherer, 2007). Specifically, there is growing evidence that unlike intelligence, EC can be taught and improved (Brasseur et al., 2013; Hodzic et al., 2017). However, the question of EC and EI measurement remains critical (Laborde \& Allen, 2016), and there is a continuous need for measurement evaluation, given the fast-paced theoretical advancements in this area (Mikolajczak, 2010), and because of the regular development of new scales (e.g., Pekaar et al., 2018). Therefore, the aim of this study is to analyse the convergent validity of two questionnaires aimed to assess EI/EC at the trait level, the trait emotional intelligence questionnaire (TEIQue; Petrides, 2009) and the profile for emotional competences (PEC; Brasseur et al., 2013).

The TEIQue (Petrides, 2009) measures a constellation of emotion-related self-perceptions situated at the lower levels of personality hierarchies (Petrides et al., 2007), reflecting how people deal with their own and others' emotions. This questionnaire has been utilised in numerous studies, which among other aspects, displayed higher predictive ability on a range of life outcomes in comparison to established personality constructs such as the big five (e.g., Siegling et al., 2015). Moreover, research has reported that EI measured with the TEIQue was connected to genetic factors (van der Linden et al., 2018; Vernon et al., 2008) and to biological mechanisms linked to stress, such as the stress hormone cortisol (Laborde et al., 2014; Mikolajczak et al., 2007), and with a marker of self-regulation, heart rate variability (Laborde et al., 2011; Laborde et al., 2015). The TEIQue is available in two versions (Petrides, 2009), a full-form version (153 items, 4 factors, 15 subscales) and a short-form version (30 items, 4 factors). The definition of the TEIQue subscales is provided in Table 1.

The PEC (Brasseur et al., 2013) measures how individuals deal with intrapersonal and interpersonal information, on the five core EC, namely identification, expression, understanding, regulation, and use of emotions. The main difference with the TEIQue is that the PEC splits explicitly each of the five main EC into two dimensions, intrapersonal and interpersonal, while the TEIQue integrates both intrapersonal and interpersonal information in its factors 


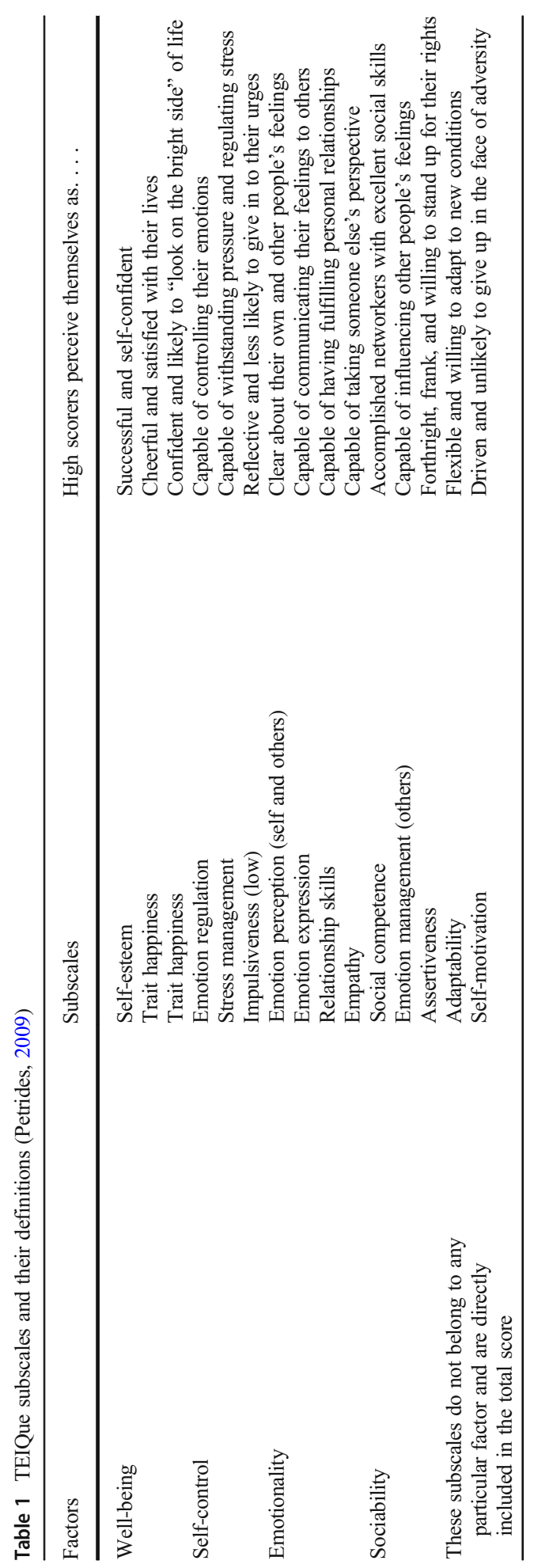


(Brasseur et al., 2013; Nozaki et al., 2019; Petrides, 2009). This distinction allows to better understand the relationship of EC with outcomes (Pekaar et al., 2020), given certain aspects may be more related to intrapersonal EC, such as health (Mikolajczak et al., 2015; Nozaki \& Koyasu, 2016), perceived stress (You et al., 2020), or executive functions (Vaughan et al., 2020), while other may be more connected to interpersonal EC, such as relationships (Brasseur et al., 2013). This intra/interpersonal distinction allows as well to better understand the relationship of EC with established personality constructs, such as with the big five (Laborde et al., 2020). Despite the PEC being a relatively new instrument in comparison to the TEIQue, empirical evidence has demonstrated its ability to predict subjective health and happiness (Nozaki \& Koyasu, 2016) as well as objective health outcomes (Mikolajczak et al., 2015). Furthermore, building on the distinction between intrapersonal and interpersonal EC, people with higher interpersonal EC were found to show higher helpful behaviour towards ostracized people (Nozaki, 2015). Additionally, taking into account the interaction between intrapersonal and interpersonal EC may help to better understand their relationship with specific psychological and physiological outcomes, such as parental burnout (Bayot et al., 2021) or anorexia nervosa (Doba \& Nandrino, 2020). The PEC full-form (Brasseur et al., 2013) has 50 items, 2 factors, and 10 subscales, while the PEC short-form has 20 items, 2 factors, and 10 subscales (Mikolajczak et al., 2014). The definition of the subscales is provided in Table 2.

To date, the convergent validity between the TEIQue and the PEC has only been briefly investigated during the validation process of the PEC (Brasseur et al., 2013). However, in this study, the TEIQue short-form was used, and therefore, only a comparison with the global trait EI (i.e., the average score of all items) could be realized. Findings showed that the PEC global score was significantly highly correlated with the TEIQue global score $(r=.77)$; however, the correlation was higher for the PEC intrapersonal factor $(r=.78)$ than with the PEC interpersonal factor $(r=.52)$. This finding would suggest that the TEIQue captures more intrapersonal than interpersonal aspects. Taking the TEIQue short-form to evaluate the convergent validity with the PEC may not be the most optimal choice, even if the factor structure is expected to be similar between the TEIQue full-form and short-form (Laborde et al., 2016). For example, the TEIQue short-form has been shown to produce systematically higher scores than the TEIQue long-form (Laborde et al., 2017), though both questionnaires remain highly correlated and predict outputs in a similar way. Therefore, to better analyse the convergent validity between the two questionnaires, we will use the full-form versions for both the TEIQue and the PEC.

In assessing the convergent validity between the TEIQue full-form and the PEC full-form, we will recruit a large sample $(N>1000)$. Given our large sample size and the likely high amount of significant correlations we will find, we will base our hypotheses on the effect size

Table 2 Profile of Emotional Competences subscales and their definitions (Brasseur et al., 2013)

\begin{tabular}{ll}
\hline Emotional competence & Definition \\
\hline $\begin{array}{l}\text { Identification (own and } \\
\text { others) }\end{array}$ & Being able to perceive an emotion when it appears and identify it \\
$\begin{array}{l}\text { Expression (own and others) } \\
\begin{array}{l}\text { Understanding (own and } \\
\text { others) }\end{array}\end{array}$ & $\begin{array}{c}\text { Being able to express emotions in a socially accepted manner } \\
\text { Being able to understand the causes and consequences of emotions, } \\
\text { and to distinguish triggering factors from causes }\end{array}$ \\
$\begin{array}{ll}\text { Regulation (own and others) } \\
\text { Being able to regulate stress or emotions when they are not appropriate to the } \\
\text { context }\end{array}$ \\
$\begin{array}{l}\text { Use (own and others) } \\
\text { Being able to use emotions to improve reflection, decisions and actions }\end{array}$ \\
\hline
\end{tabular}


of the relationships, and predict only the relationships where large effect sizes, with $r>.50$ (Cohen, 1988), can be expected based on theoretical considerations (Brasseur et al., 2013; Petrides, 2009). Hypotheses take as a reference point the PEC subscales and factors, based on their organization into intrapersonal and interpersonal EC (see Table 3). For clarity and space matters, hypotheses are only made either at the subscale level, or at the factor/global trait level. Therefore, no hypotheses are made between subscales of one questionnaire and factors of the other questionnaire.

\section{Methods}

\section{Participants}

A total of 1026 students were involved in this research (516 male, 510 female, mean age $=21.35$ years old, age range $=18-30$ years old). Participants had to be at least 18 to participate, and to study at the local University. There were no further inclusion or exclusion criteria.

\section{Instruments}

\section{Trait Emotional Intelligence Questionnaire (TEIQue)}

The Spanish version of the TEIQue was used in this research (Petrides, 2009). The TEIQue full-form (Petrides, 2009) contains 153 items, 15 subscales, and four factors. The four factors are well-being (e.g., "On the whole, I'm pleased with my life"), self-control (e.g., "Others admire me for being relaxed."), emotionality (e.g., "I often pause and think about my feelings"), and sociability (e.g., "I would describe myself as a good negotiator"). The 15 subscales are self-esteem, emotion expression, motivation, emotion regulation, happiness, empathy, social competence, impulsiveness, emotion perception, stress management, emotion

Table 3 Hypothesised significant correlations with large effect sizes

\begin{tabular}{ll}
\hline PEC subscales & TEIQue subscales \\
\hline Identification (own) & Emotion perception (self and others) \\
Identification (others) & Emotion perception (self and others), empathy, relationship skills \\
Understanding (own) & Emotion perception (self and others) \\
Understanding (others) & Emotion perception (self and others), empathy, relationship skills \\
Expressing (own) & Emotion expression \\
Expressing (others) & Relationship skills \\
Regulation (own) & Emotion regulation, stress management \\
Regulation (others) & Emotion management (others), relationship skills \\
Use (own) & None \\
Use (others) & Emotion management (others), relationship skills \\
PEC factors and global score & TEIQue factors and global score \\
Intrapersonal EC & Well-being, self-control, emotionality, TEIQue global \\
Interpersonal EC & Emotionality, sociability, TEIQue global \\
Global EC & Well-being, self-control, emotionality, sociability, TEIQue global \\
\hline
\end{tabular}

Notes: TEIQue, Trait Emotional Intelligence Questionnaire; PEC, Profile of Emotional Competences; EC, Emotional Competences 
management, optimism, relationship skills, adaptability, and assertiveness. Items are scored on a Likert-scale from 1 (completely disagree) to 7 (completely agree). Cronbach's $\alpha$ are displayed in Table 4.

\section{Profile of Emotional Competences}

The PEC (Brasseur et al., 2013) contains 50 items, assessed from 1 (strongly disagree) to 5 (strongly agree) on a Likert-scale. It measures five core EC separately, distinctly for one's own and others' emotions. Ten subscales can be thus calculated: identification of one's emotions,

Table 4 Descriptive statistics

\begin{tabular}{|c|c|c|c|}
\hline & M & $\mathrm{SD}$ & Cronbach's $\alpha$ \\
\hline \multicolumn{4}{|l|}{ TEIQue } \\
\hline \multicolumn{4}{|l|}{ Subscales } \\
\hline Self-esteem & 4.74 & 0.82 & 0.76 \\
\hline Emotion expression & 4.32 & 1.07 & 0.83 \\
\hline Motivation & 4.73 & 0.84 & 0.73 \\
\hline Emotion regulation & 4.17 & 0.72 & 0.68 \\
\hline Happiness & 5.55 & 0.98 & 0.82 \\
\hline Empathy & 4.94 & 0.83 & 0.73 \\
\hline Social competence & 4.67 & 0.76 & 0.71 \\
\hline Impulsiveness & 4.45 & 0.87 & 0.7 \\
\hline Emotion perception & 4.52 & 0.80 & 0.69 \\
\hline Stress management & 4.34 & 0.84 & 0.7 \\
\hline Emotion management & 4.38 & 0.78 & 0.69 \\
\hline Optimism & 5.18 & 0.96 & 0.81 \\
\hline Relationship skills & 5.29 & 0.81 & 0.7 \\
\hline Adaptability & 4.41 & 0.75 & 0.69 \\
\hline Assertiveness & 4.68 & 0.77 & 0.66 \\
\hline \multicolumn{4}{|l|}{ Factors } \\
\hline Well-being & 5.16 & 0.81 & 0.85 \\
\hline Self-control & 4.32 & 0.68 & 0.79 \\
\hline Emotionality & 4.77 & 0.68 & 0.77 \\
\hline Sociability & 4.58 & 0.62 & 0.73 \\
\hline \multicolumn{4}{|l|}{ Global score } \\
\hline Global TEIQue & 4.69 & 0.54 & 0.79 \\
\hline \multicolumn{4}{|l|}{ PEC } \\
\hline \multicolumn{4}{|l|}{ Subscales } \\
\hline Identification_own & 3.64 & 0.67 & 0.7 \\
\hline Identification_others & 3.52 & 0.70 & 0.72 \\
\hline Understanding_own & 3.55 & 0.73 & 0.71 \\
\hline Understanding_others & 3.37 & 0.63 & 0.72 \\
\hline Expressing_own & 3.38 & 0.74 & 0.73 \\
\hline Expressing_others & 3.87 & 0.73 & 0.76 \\
\hline Regulation_own & 3.21 & 0.71 & 0.73 \\
\hline Regulation_others & 3.36 & 0.66 & 0.72 \\
\hline Use_own & 3.52 & 0.62 & 0.7 \\
\hline Use_others & 2.97 & 0.75 & 0.78 \\
\hline \multicolumn{4}{|l|}{ Factors } \\
\hline Intrapersonal_EC & 3.46 & 0.49 & 0.87 \\
\hline Interpersonal_EC & 3.42 & 0.51 & 0.88 \\
\hline \multicolumn{4}{|l|}{ Global score } \\
\hline Global EC & 3.44 & 0.45 & 0.92 \\
\hline
\end{tabular}

Notes: TEIQue, Trait Emotional Intelligence Questionnaire; PEC, Profile of Emotional Competences 
identification of others' emotions, understanding of one's emotions, understanding of others' emotions, expression of one's emotions, listening to others' emotions, regulation of one's emotions, regulation of others' emotions, use of one's emotions, use of others' emotions. Three global scores can be calculated: an intrapersonal EC score, an interpersonal EC score, and a global EC score. Examples of items are "during an argument, I can't identify whether I am sad or angry" and "my emotions inform me of what is important to me". Given the PEC was not available in Spanish, a preliminary step was to validate the PEC to Spanish. This preliminary step is described in the procedure and data analysis sections. Cronbach's $\alpha$ of the validated version are displayed in Table 4.

\section{Procedure}

Given the PEC was not available in Spanish, the first step was to translate and validate the questionnaire into Spanish. To achieve this aim, guidelines from Van de Vijver and Hambleton (1996) were followed. A double back-translation procedure was used to adapt the questionnaire from English to Spanish. Two fully bilingual Spanish university professors translated the questionnaire into Spanish, which was then back translated independently by two fully bilingual English native professors (originating from Great Britain), all with educational background in psychology. Items were discussed until consensus was reached among the authors.

Once the PEC was translated to Spanish, the data collection for this study could start. The Ethics committee of a University in Spain provided ethical clearance for the study prior to data collection. Participants were recruited via research assistants trained to questionnaire data collection by the second author. Taking part in this research protocol was not part of a course requirement, and participants did not receive any payment in exchange of participation. Participants were presented with a brief description of the study objective and were then given the opportunity to participate. The research assistants made clear that participation was voluntary, anonymous, and that participants could withdraw at any time. Written informed consent was obtained from all study participants. Questionnaires were completed in a quiet classroom setting and took between 35 and 45 min to complete. The order of the two questionnaires was counterbalanced.

\section{Data Analysis}

Data of the PEC and TEIQue were first checked for normality. As our preliminary aim was to confirm the structure of the PEC in Spanish, we ran a Confirmatory Factor Analysis (CFA) with AMOS 17 on our sample, with the following fit indices: the $\chi^{2}$ statistic, the comparative fit index (CFI), the Tucker-Lewis index (TLI), the root mean square of approximation (RMSEA), the standardized root mean square residual (SRMR). The $\chi^{2}$ statistic constitutes a subjective index of fit, with large chi-square values relative to degrees of freedom indicating a poor fit, and small values indicating a good fit (Jöreskog, 1993). However, $\chi^{2}$ is quite sensitive to sample size and inflates with large samples (Raykov, 1998). For the CFI and the TLI, values between .90 and .94 indicate acceptable fit, whereas values of .95 and higher indicate a relatively good fit (Hu \& Bentler, 1999). For the RMSEA, values smaller than .08 indicate acceptable fit, whereas values smaller than .05 indicate a good fit. For SRMR, a good fit is indicated by values smaller than .08 (Hu \& Bentler, 1999). 
To analyse the convergent validity between the PEC and the TEIQue, bivariate Pearson correlation analyses were run. Given the large sample size and the likely high associations between two self-report questionnaires aiming to assess EI at the trait level, we formulated our hypotheses not only taking into account the significance level but also the effect size, considering only large effect sizes, so with $r>.50$.

\section{Results}

\section{CFA}

As a model for the CFA, we took the ten subscales and the two main factors of the PEC to see whether the original structure would replicate in the Spanish sample. The first CFA indicated acceptable fit to the data: $\chi^{2}=299.161, d f=34, p<.001, \mathrm{CFI}=.93$, TLI $=.90$, RMSEA $=.08$, $\mathrm{SRMR}=.05$. However, analysis of the modification indices (M.I.) suggested that correlating the error variance between two subscales from the interpersonal factor, namely "regulating others' emotions" and "using others' emotions", would improve model fit (value modification index $=142.273$ ). Thus, our final CFA model indicated a good fit to the data supporting the PEC factor structure in a Spanish sample: $\chi^{2}=146.049, d f=33, p<.001, \mathrm{CFI}=.97$, TLI $=$ $.96, \mathrm{RMSEA}=.06, \mathrm{SRMR}=.03$.

\section{Convergent Validity}

An overview of the descriptive data can be seen in Table 4, and the correlation matrix can be seen in Table 5.

\section{Discussion}

The aim of this study was to investigate the convergent validity between two questionnaires aiming to measure EI/EC at the trait level, the PEC and the TEIQue. Our hypotheses regarding the associations between both questionnaires with large effect sizes were mostly confirmed; however, certain discrepancies appeared, showing that both scales provide unique information.

\section{Validation of the PEC to Spanish}

As a preliminary step, we needed to validate the PEC to Spanish. While checking whether the data from the Spanish sample was matching the original structure of the PEC in 10 subscales and 2 factors, it appeared necessary to correlate the error variance of two dimensions from the interpersonal factor, "regulating others' emotions" and "using others' emotions". According to Brasseur et al. (2013), the first dimension refers to being able to regulate stress or emotions in others when they are not appropriate to the context. The second refers to being able to use others' emotions to help them improve reflection, decisions, and actions. Even though both competences are conceptually distinct, we observed some overlap between them, in that using others' emotions could be seen as regulating others' emotions with the objective to achieve a specific goal. 


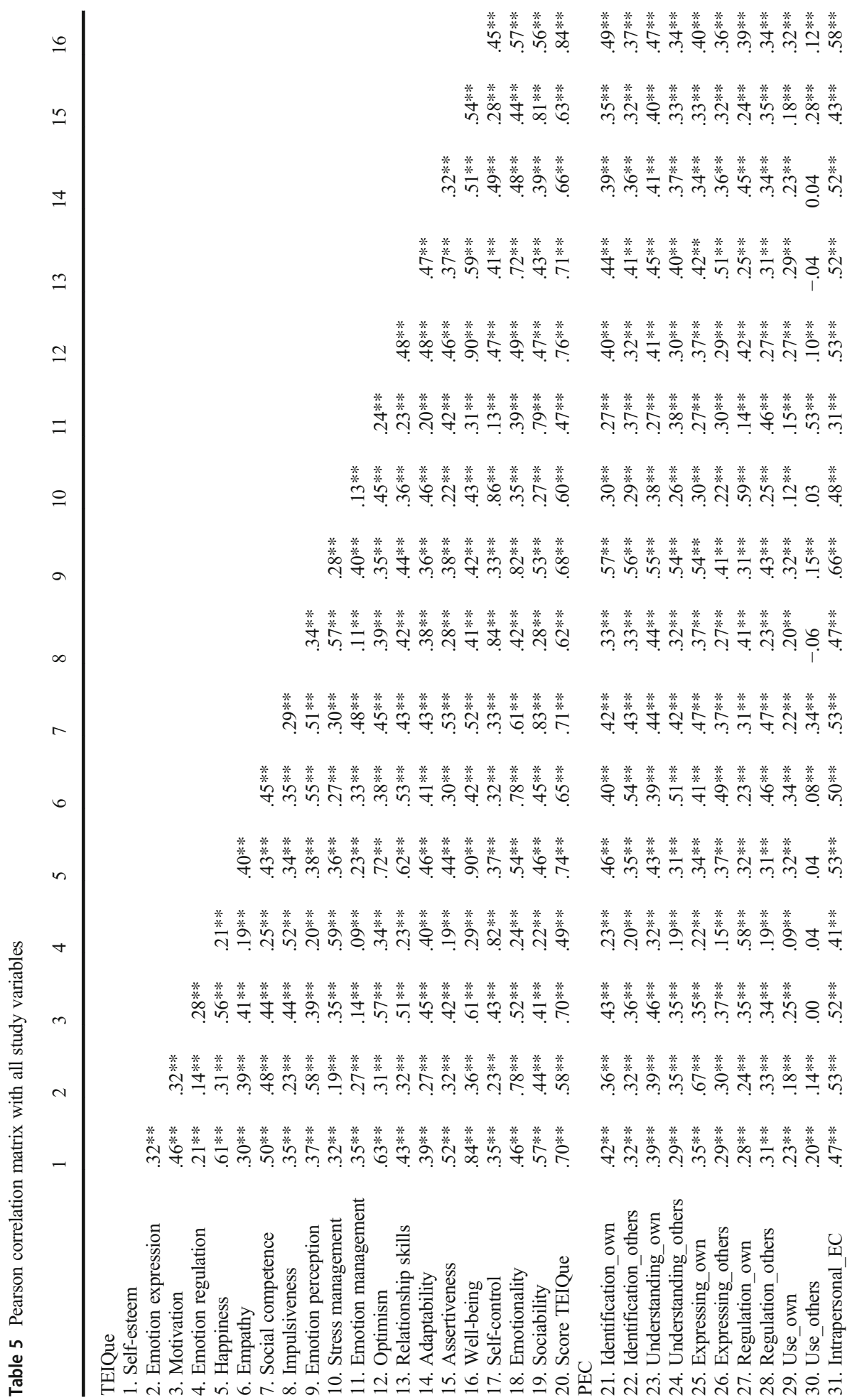




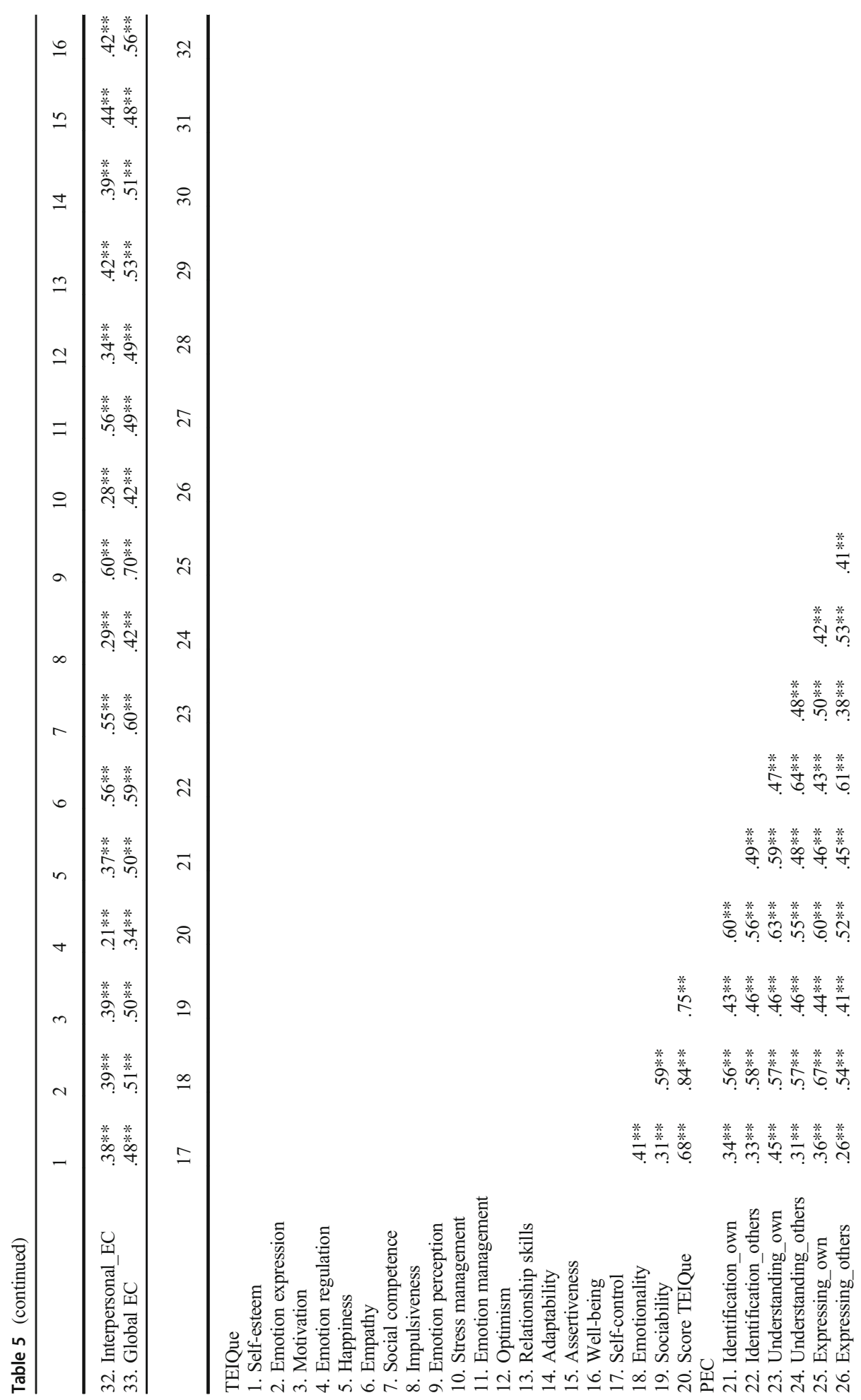




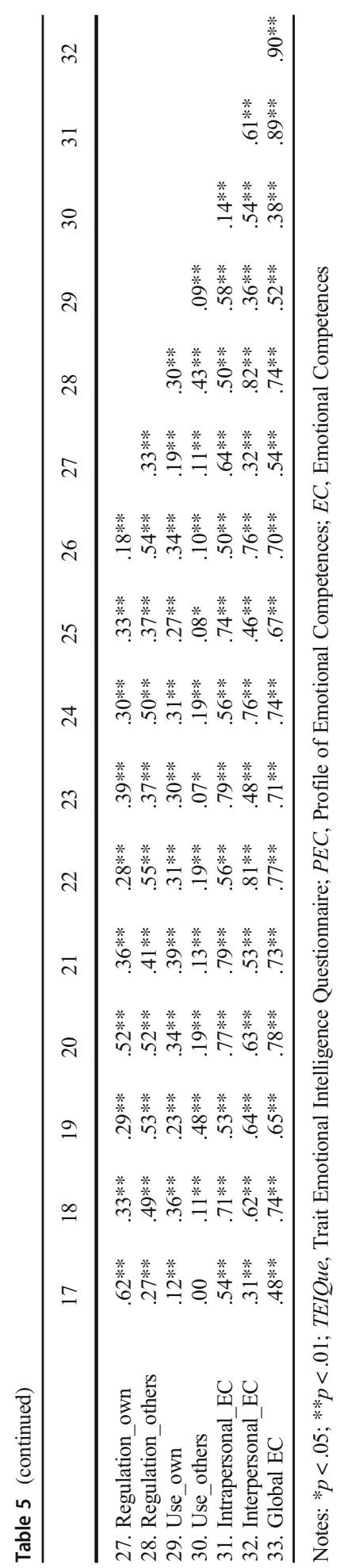




\section{Convergent Validity between the TEIQue and the PEC}

The main aim of this study was to analyse the convergent validity between the TEIQue and the PEC, and we will discuss these in turn regarding our hypotheses (see Table 3) using the PEC subscales as a reference point.

Regarding the PEC subscale "identification of one's emotions", our hypothesis was confirmed, with a significant correlation and large effect size found with the TEIQue subscale "emotion perception (self and others)". Regarding the PEC subscale "identification of others' emotions", our hypothesis is partially confirmed, given we found a significant correlation and large effect size with the TEIQue subscales "emotion perception (self and others)" and "empathy", but not with relationship skills. This means that the TEIQue subscale "relationship skills", defined as "being capable of having fulfilling personal relationships" (Petrides, 2009), captures additional variance beyond aspects related to identifying others' emotions.

Regarding the PEC subscale "understanding of one's emotions", our hypothesis is confirmed, with a significant correlation and large effect size found with the TEIQue subscale "emotion perception (self and others)". This finding illustrates the notion that perceiving emotion in the self and others plays a major role in being able to understand one's emotions. Regarding the PEC subscale "understanding of others' emotions", our hypothesis is partially confirmed, given we found a significant correlation and large effect size with the TEIQue subscales "emotion perception (self and others)" and "empathy", but not with the TEIQue subscale "relationship skills". This means that the TEIQue subscale "relationship skills" captures additional variance beyond aspects related to understanding others' emotions.

Regarding the PEC subscale "expressing one's emotions", our hypothesis was partially confirmed, with a significant correlation and large effect size found with the TEIQue subscale "emotion expression". However, a significant correlation and large effect size was also found with the TEIQue subscale "emotion perception (self and others)". This finding may illustrate the need to be able to perceive one's own and others' emotions, if one wants also to be able to express one's emotions satisfactorily.

Regarding the PEC subscale "regulating one's emotions", our hypothesis is confirmed. We found as expected a significant correlation and large effect size with the TEIQue subscales "emotion regulation" and "stress management". In the literature, stress is generally seen as a general adaptation mechanism, whereas emotions can be considered as responses triggered by specific appraisals, and have also a specific purpose regarding the goal to be achieved (Lazarus \& Folkman, 1984; Scherer, 2005; Selye, 1951). This finding matches the PEC subscale "regulating one's emotions" which encompasses both stress and emotion regulation (Brasseur et al., 2013). Regarding the PEC subscale "regulating others' emotions", our hypothesis was not confirmed. We expected a significant correlation and large effect sizes with two TEIQue subscales, "emotion management (others)" and "relationship skills"; however, these produced only moderate effect sizes. Overall, the PEC subscale "regulating others' emotions" indicated no correlation with any of the TEIQue subscales, which argues that this subscale's conceptual uniqueness is not captured by any TEIQue subscale.

Regarding the PEC subscale "using one's emotions", our hypothesis is confirmed, given only a significant correlation and moderate effect size was found with the TEIQue subscale "adaptability". No other large effect was observed with any of the other TEIQue subscales. This finding suggests a unique feature of the PEC in contrast to the TEIQue in conceptualizing and measuring the use of one's emotions, which is a core competence reflecting the integration of emotions into the optimization process of goal-directed behaviours. 
Regarding the PEC subscale "using others' emotions", our hypothesis is partially validated. A significant correlation and large effect size was found with the TEIQue subscale "emotion regulation"; however, no correlation was found with the TEIQue subscale "relationship skills". This illustrates that the TEIQue subscale "relationship skills", the ability in being capable of having fulfilling personal relationships (Petrides, 2009), does not integrate the notion of being able to use others' emotions to help them make more adaptive decisions or realize more adaptive actions (Brasseur et al., 2013).

Regarding the PEC factor intrapersonal EC, our hypothesis was partially confirmed. As expected, we found intrapersonal EC to correlate significantly with large effect sizes with three TEIQue factors theoretically reflecting intrapersonal EC (i.e., well-being, self-control, and emotionality) and with the global TEIQue score, in line with the assumption that the TEIQue mostly focuses on intrapersonal EC (Brasseur et al., 2013; Petrides, 2009). In addition, we found a positive significant correlation with large effect size with the TEIQue factor sociability. This is potentially due to the fact that sociability encompasses two facets that may rely on interpersonal EC: social competence, which describes accomplished networkers with excellent social skills, and assertiveness, which reflects one's willingness to stand up for their rights (Petrides, 2009). Regarding interpersonal EC, our hypothesis to find a significant relationship with large effect sizes only with the TEIQue global score and with the TEIQue factors emotionality and sociability but not with the TEIQue factors well-being and self-control was confirmed. The TEIQue factors well-being and self-control showed only moderate correlations with the PEC factor interpersonal EC, while displaying at the same time large correlations with the PEC factor intrapersonal EC, which reflects that the TEIQue factors well-being and self-control are more strongly based on intrapersonal EC. Finally, our hypothesis regarding the PEC global score was partially confirmed, given it was correlated with large effect sizes with the TEIQue global score and all TEIQue factors but one. Specifically, only a moderate effect size was found between the global PEC score and the TEIQue factor self-control, meaning that self-control, the ability to control impulses and urges (Petrides, 2009), is not strongly reflected in the PEC global score.

To sum up, the PEC and the TEIQue show convergent validity in many aspects, but also displayed some unique features that make them conceptually different from each other. As evidenced by our findings, and in line with theoretical considerations underlying the PEC and the TEIQue (Brasseur et al., 2013; Nozaki et al., 2019; Petrides, 2009), the main distinction is that the PEC differentiates explicitly and systematically competences related to intrapersonal and interpersonal emotions, while the TEIQue aggregates both, with some TEIQue subscales spanning both aspects, while other TEIQue subscales target specifically only one aspect. This characteristic can be considered a limitation of the TEIQue, given being able to differentiate clearly between intrapersonal and interpersonal emotional process appears critical both conceptually and at the applied level when designing interventions. Furthermore, the PEC seems to have a unique feature in considering the competence "using". Indeed, the TEIQue global score displayed correlations and large effect sizes on all PEC factors and subscales, besides the PEC subscales "using one's emotions" and "using others' emotions". However, the PEC subscale "using others' emotions" indicated a large correlation with the TEIQue subscale "emotion management (others)", and the PEC subscale "using one's emotions" does not show any correlation with large effect size with any TEIQue subscales. This finding points towards a unique characteristic of the PEC concerning its ability to measure the competence "using emotions" for both self and others, which the TEIQue does not address. This has both theoretical and applied consequences, given using one's and others' emotions is critical to make the most adaptive decisions and realize the most adaptive actions (Brasseur et al., 2013). 


\section{Limitations}

Our study had some strengths (e.g., large sample size), but had also some limitations. For example, the sample comprised only students, and therefore results cannot be generalized to different populations. Future research should therefore investigate the convergent validity between the PEC and the TEIQue in other samples, as well as in other cultures. In addition, history of any psychiatric diagnosis or medicine use related to emotional dispositions was not controlled for. Moreover, some Cronbach's $\alpha$ of the TEIQue subscales are just below the acceptable threshold of .70: emotion regulation (.68), emotion perception (.69), emotion management (.69), adaptability (.69), and assertiveness (.66), which suggests caution while interpreting the findings related to these subscales.

\section{Conclusion}

To further compare the validity of the two questionnaires, future research should test the PEC and the TEIQue concurrently in terms of outcomes, criterion validity, and relationships with ability measures of EI/EC, for example, in the same vein as Freudenthaler and Neubauer (2005), who tested the convergent and discriminant validities of intra- and interpersonal emotional abilities with relevant performance measures. Furthermore, the question of adapting the questionnaires to specific samples/areas of applications appears relevant, like it was done with the PEC for cancer patients (Baudry et al., 2020). In addition, the effort in determining the best way to assess EI/EC at the trait level appears worthwhile, given its importance in many domains. Noteworthy, a recent finding (Mikolajczak \& Van Bellegem, 2017) showed that every $1 \%$ increase in intrapersonal EC, as measured with the PEC, was found to correspond to $1 \%$ decrease in healthcare expenditure. Specifically, further investigation of EI/EC with a clear distinction between intrapersonal and interpersonal EI/EC appears important for addiction research. For example, to determine their implication and impact on different kinds of addictions, such as smoking, alcohol use, illicit drug use (Kun \& Demetrovics, 2010), or addiction focusing on technology (Gugliandolo et al., 2019), such as addictions related to internet behaviours (Arrivillaga et al., 2020; Hsieh et al., 2018; Sechi et al., 2020; Wang \& Zhang, 2020), and smartphone use (Arrivillaga et al., 2020; Busch \& McCarthy, 2021; Mascia et al., 2020). Finally, clarifying the role of intra- and interpersonal EC would also help to design more specific interventions (Hodzic et al., 2017; Schütz et al., 2020), and promote healthy emotional growth of individuals, protecting against addictions as suggested by many researchers in this domain (Arrivillaga et al., 2020; Busch \& McCarthy, 2021; Gugliandolo et al., 2019; Kun \& Demetrovics, 2010; Mascia et al., 2020).

Acknowledgements We would like to thank the members of the research group of Prof. Dr. Dr. Markus Raab, Institute of Psychology, Department of Performance Psychology, Cologne, Germany, for their critical and helpful comments.

Funding Open Access funding enabled and organized by Projekt DEAL.

\section{Compliance with Ethical standards}

Conflict of Interest The authors have no conflict of interest to declare. 
Ethical Approval Ethics approval has been obtained from the University Ethics board of FG.

Open Access This article is licensed under a Creative Commons Attribution 4.0 International License, which permits use, sharing, adaptation, distribution and reproduction in any medium or format, as long as you give appropriate credit to the original author(s) and the source, provide a link to the Creative Commons licence, and indicate if changes were made. The images or other third party material in this article are included in the article's Creative Commons licence, unless indicated otherwise in a credit line to the material. If material is not included in the article's Creative Commons licence and your intended use is not permitted by statutory regulation or exceeds the permitted use, you will need to obtain permission directly from the copyright holder. To view a copy of this licence, visit http://creativecommons.org/licenses/by/4.0/.

\section{References}

Arrivillaga, C., Rey, L., \& Extremera, N. (2020). Adolescents' problematic internet and smartphone use is related to suicide ideation: Does emotional intelligence make a difference? Computers in Human Behavior, 110. https://doi.org/10.1016/j.chb.2020.106375.

Baudry, A. S., Christophe, V., Constant, E., Piessen, G., Anota, A., \& Group, F. W. (2020). The Profile of Emotional Competence (PEC): A French short version for cancer patients. PLoS One, 15(6), e0232706. https://doi.org/10.1371/journal.pone.0232706.

Bayot, M., Roskam, I., Gallee, L., \& Mikolajczak, M. (2021). When emotional intelligence backfires interactions between intra- and interpersonal emotional competencies in the case of parental burnout. Journal of Individual Differences, 42(1), 1-8. https://doi.org/10.1027/1614-0001/a000324.

Brasseur, S., Grégoire, J., Bourdu, R., \& Mikolajczak, M. (2013). The Profile of Emotional Competence (PEC): Development and validation of a self-reported measure that fits dimensions of emotional competence theory. PLoS One, 8, 1-8. https://doi.org/10.1371/journal.pone.0062635.

Busch, P. A., \& McCarthy, S. (2021). Antecedents and consequences of problematic smartphone use: A systematic literature review of an emerging research area. Computers in Human Behavior, 114, 106414. https://doi.org/10.1016/j.chb.2020.106414.

Cohen, D. (1988). Statistical power analysis for behavioral sciences. Hillsdale.

Doba, K., \& Nandrino, J. L. (2020). Cognitive and emotional empathy in anorexia nervosa: The role of attachment insecurity, intrapersonal, and interpersonal emotional competences. Journal of Nervous and Mental Disease, 208(4), 312-318. https://doi.org/10.1097/NMD.0000000000001130.

Freudenthaler, H. H., \& Neubauer, A. C. (2005). Emotional intelligence: The convergent and discriminant validities of intra- and interpersonal emotional abilities. Personality and Individual Differences, 39, 569-579.

Gugliandolo, M. C., Costa, S., Kuss, D. J., Cuzzocrea, F., \& Verrastro, V. (2019). Technological addiction in adolescents: The interplay between parenting and psychological basic needs. International Journal of Mental Health and Addiction, 18(5), 1389-1402. https://doi.org/10.1007/s11469-019-00156-4.

Hodzic, S., Scharfen, J., Ripoll, P., \& Zenasni, F. (2017). How efficient are emotional intelligence trainings: A meta-analysis. Emotion Review. https://doi.org/10.1177/1754073917708613.

Hsieh, Y.-P., Wei, H.-S., Hwa, H.-L., Shen, A. C.-T., Feng, J.-Y., \& Huang, C.-Y. (2018). The effects of peer victimization on children's internet addiction and psychological distress: The moderating roles of emotional and social intelligence. Journal of Child and Family Studies, 28(9), 2487-2498. https://doi.org/10.1007/ s10826-018-1120-6.

Hu, L., \& Bentler, P. (1999). Cutoff criteria for fit indexes in covariance structure analysis: Conventional criteria versus new alternatives. Structural Equation Modeling, 6, 1-55. https://doi.org/10.1080/ 10705519909540118.

Jöreskog, K. G. (1993). Testing structural equation models. In K. A. Bollen \& J. S. Long (Eds.), Testing structural equation models (pp. 294-316). Newbury Park, CA: Sage.

Kun, B., \& Demetrovics, Z. (2010). Emotional intelligence and addictions: A systematic review. Substance Use \& Misuse, 45, 1131-1160. https://doi.org/10.3109/10826080903567855.

Laborde, S., \& Allen, M. S. (2016). Comment: Measurement and the interpretation of trait EI research. Emotion Review., 8, 342-343. https://doi.org/10.1177/1754073916650498.

Laborde, S., Brüll, A., Weber, J., \& Anders, L. S. (2011). Trait emotional intelligence in sports: A protective role against stress through heart rate variability? Personality and Individual Differences, 51, 23-27. https:/doi. org/10.1016/j.paid.2011.03.003.

Laborde, S., Lautenbach, F., Allen, M. S., Herbert, C., \& Achtzehn, S. (2014, Jan). The role of trait emotional intelligence in emotion regulation and performance under pressure. Personality and Individual Differences, 57, 43-47. https://doi.org/10.1016/J.Paid.2013.09.013. 
Laborde, S., Lautenbach, F., \& Allen, M. S. (2015, Feb). The contribution of coping-related variables and heart rate variability to visual search performance under pressure. Physiology \& Behavior, 139, 532-540. https:// doi.org/10.1016/j.physbeh.2014.12.003.

Laborde, S., Allen, M. S., \& Guillén, F. (2016). Construct and concurrent validity of the short- and long-form versions of the trait emotional intelligence questionnaire. Personality and Individual Differences, 101, 232235. https://doi.org/10.1016/j.paid.2016.06.009.

Laborde, S., Guillén, F., \& Watson, M. (2017). Trait emotional intelligence questionnaire full-form and shortform versions: Links with sport participation frequency and duration and type of sport practiced. Personality and Individual Differences, 108, 5-9. https://doi.org/10.1016/j.paid.2016.11.061.

Laborde, S., Gerlach, S., \& Vaughan, R. (2020). Hitchhiking: Associations with big five and emotional competences. Psychological Reports., 003329412095355. https://doi.org/10.1177/0033294120953556.

Lazarus, R. S., \& Folkman, S. (1984). Stress, appraisal and coping. Springer.

Mascia, M. L., Agus, M., \& Penna, M. P. (2020). Emotional intelligence, self-regulation, smartphone addiction: Which relationship with student well-being and quality of life? Frontiers in Psychology, 11, 375. https://oi. org/10.3389/fpsyg.2020.00375.

Mikolajczak, M. (2010). Going beyond the ability-trait debate: The three-level model of emotional intelligence. E-Journal of Applied Psychology, 5(2). https://doi.org/10.7790/ejap.v5i2.175.

Mikolajczak, M., \& Van Bellegem, S. (2017). Increasing emotional intelligence to decrease healthcare expenditures: How profitable would it be? Personality and Individual Differences, 116, 343-347. https://doi.org/ 10.1016/j.paid.2017.05.014.

Mikolajczak, M., Roy, E., Luminet, O., Fillée, C., \& de Timary, P. (2007). The moderating impact of emotional intelligence on free cortisol responses to stress. Psychoneuroendocrinology, 32, 1000-1012. https://doi.org/ 10.1016/j.psyneuen.2007.07.009.

Mikolajczak, M., Brasseur, S., \& Fantini-Hauwel, C. (2014). Measuring intrapersonal and interpersonal EQ: The Short Profile of Emotional Competence (S-PEC). Personality and Individual Differences, 65, 42-46. https:// doi.org/10.1016/j.paid.2014.01.023.

Mikolajczak, M., Avalosse, H., Vancorenland, S., Verniest, R., Callens, M., van Broeck, N., Fantini-Hauwel, C., \& Mierop, A. (2015, Oct). A nationally representative study of emotional competence and health. Emotion, 15(5), 653-667. https://doi.org/10.1037/emo0000034.

Nozaki, Y. (2015, Dec). Emotional competence and extrinsic emotion regulation directed toward an ostracized person. Emotion, 15(6), 763-774. https://doi.org/10.1037/emo0000081.

Nozaki, Y., \& Koyasu, M. (2016, Feb). Can we apply an emotional competence measure to an eastern population? Psychometric properties of the profile of emotional competence in a Japanese population. Assessment, 23(1), 112-123. https://doi.org/10.1177/1073191115571124.

Nozaki, Y., Puente-Martinez, A., \& Mikolajczak, M. (2019). Evaluating the higher-order structure of the Profile of Emotional Competence (PEC): Confirmatory factor analysis and Bayesian structural equation modeling. PLoS One, 14(11), e0225070. https://doi.org/10.1371/journal.pone.0225070.

Pekaar, K. A., Bakker, A. B., van der Linden, D., \& Born, M. P. (2018). Self- and other-focused emotional intelligence: Development and validation of the Rotterdam Emotional Intelligence Scale (REIS). Personality and Individual Differences, 120, 222-233. https://doi.org/10.1016/j.paid.2017.08.045.

Pekaar, K. A., van der Linden, D., Bakker, A. B., \& Born, M. P. (2020). Dynamic self- and other-focused emotional intelligence: A theoretical framework and research agenda. Journal of Research in Personality, 86. https://doi.org/10.1016/j.jrp.2020.103958.

Petrides, K. V. (2009). Technical manual for the Trait Emotional Intelligence Questionnaire (TEIQue). London Psychometric Laboratory.

Petrides, K. V., Pita, R., \& Kokkinaki, F. (2007). The location of trait emotional intelligence in personality factor space. British Journal of Psychology, 98, 273-289. https://doi.org/10.1348/000712606X120618.

Petrides, K. V., Mikolajczak, M., Mavroveli, S., Sanchez-Ruiz, M. J., Furnham, A., \& Perez-Gonzalez, J. C. (2016, Oct). Developments in trait emotional intelligence research. Emotion Review, 8(4), 335-341. https:// doi.org/10.1177/1754073916650493.

Raykov, T. (1998). On the use of confirmatory factor analysis in personality research. Personality and Individual Differences, 24, 291-293.

Salovey, P., \& Mayer, J. D. (1990). Emotional intelligence. Imagination, Cognition, and Personality, 9, $185-211$.

Sarrionandia, A., \& Mikolajczak, M. (2020, Jun). A meta-analysis of the possible behavioural and biological variables linking trait emotional intelligence to health. Health Psychology Review, 14(2), 220-244. https:// doi.org/10.1080/17437199.2019.1641423.

Scherer, K. R. (2005). What are emotions? And how can they be measured? Social Science Information, 44, 695729. https://doi.org/10.1177/0539018405058216. 
Scherer, K. R. (2007). Componential emotion theory can inform models of emotional competence. In G. Matthews, M. Zeidner, \& R. Roberts (Eds.), The science of emotional intelligence: Knowns and unknowns (pp. 101-126). Oxford University Press.

Schütz, K., Rahders, F., Mosley, E., \& Laborde, S. (2020). Emotional competences training in equestrian sport A preliminary study. International Journal of Sport and Exercise Psychology, 1-13. https://doi.org/10.1080/ 1612197x.2020.1819367.

Sechi, C., Loi, G., \& Cabras, C. (2020). Addictive internet behaviors: The role of trait emotional intelligence, self-esteem, age, and gender. Scandinavian Journal of Psychology. https://doi.org/10.1111/sjop.12698.

Selye, H. (1951). The general adaptation syndrome and the diseases of adaptation. The American Journal of Medicine, 10, 549-555. https://doi.org/10.1016/0002-9343(51)90327-0.

Siegling, A. B., Vesely, A. K., Petrides, K. V., \& Saklofske, D. H. (2015). Incremental validity of the Trait Emotional Intelligence Questionnaire-short form (TEIQue-SF). Journal of Personality Assessment, 1-11, 525-535. https://doi.org/10.1080/00223891.2015.1013219.

Smith, J. D., Lassiter, P. S., \& Gutierrez, D. (2020). Examining the relationship of emotional intelligence and cultural empathy in addiction counselors. Journal of Addictions \& Offender Counseling, 41(2), 97-110. https://doi.org/10.1002/jaoc.12083.

Testing structural equation models (1993) Testing structural equation models 294-316

Torres, O. V., Estep, J. C., Gwin, M., \& Villalta, I. (2020). Gender differences in negative mood, emotional intelligence and tobacco use among young adults. Substance Use \& Misuse, 55(11), 1881-1891. https://doi. org/10.1080/10826084.2020.1775649.

Van de Vijver, F., \& Hambleton, R. K. (1996). Translating tests: Some practical guidelines. European Psychologist, 1, 89-99. https://doi.org/10.1027/1016-9040.1.2.89.

van der Linden, D., Schermer, J. A., de Zeeuw, E., Dunkel, C. S., Pekaar, K. A., Bakker, A. B., Vernon, P. A., \& Petrides, K. V. (2018). Overlap between the general factor of personality and trait emotional intelligence: A genetic correlation study. Behavior Genetics, 48(2), 147-154. https://doi.org/10.1007/s10519-017-9885-8.

Vaughan, R., Hagyard, J. D., Brimmell, J., \& Edwards, E. J. (2020). The effect of trait emotional intelligence on working memory across athletic expertise. Journal of Sports Sciences, 39, 1-9. https://doi.org/10.1080/ 02640414.2020.1840039.

Vernon, P. a., Villani, V. C., Schermer, J. A., \& Petrides, K. V. (2008). Phenotypic and genetic associations between the big five and trait emotional intelligence. Twin Research and Human Genetics, 11, 524-530. https://doi.org/10.1375/twin.11.5.524.

Wang, S., \& Zhang, D. (2020). The impact of perceived social support on students' pathological internet use: The mediating effect of perceived personal discrimination and moderating effect of emotional intelligence. Computers in Human Behavior, 106. https://doi.org/10.1016/j.chb.2020.106247.

You, M., Laborde, S., Dosseville, F., Salinas, A., \& Allen, M. S. (2020). Associations of chronotype, Big Five, and emotional competences with perceived stress in university students. Chronobiology International, 1-9. https://doi.org/10.1080/07420528.2020.1752705.

Publisher's Note Springer Nature remains neutral with regard to jurisdictional claims in published maps and institutional affiliations.

\section{Affiliations}

\section{Sylvain Laborde ${ }^{1,2} \cdot$ Félix Guillén $^{3} \cdot$ Robert Vaughan ${ }^{4}$}

1 German Sport University Cologne - Institute of Psychology - Department of Performance Psychology, Cologne, Germany

2 CESAMS EA 4260, Normandie Université, 14000 Caen, France

3 University of Las Palmas de Gran Canaria, Las Palmas de Gran Canaria, Spain

4 School of Psychological and Social Sciences, York St John University, York, UK 